\title{
Targeting Endothelial CD146 Attenuates Colitis and Prevents Colitis-Associated Carcinogenesis
}

\author{
Shu Xing, ${ }^{*}$ Yongting Luo, ${ }^{*}$ Zhihua Liu, ${ }^{*}$ Pengcheng Bu, ${ }^{*}$ Hongxia Duan, ${ }^{*}$ Dan Liu, ${ }^{*}$ Ping Wang, ${ }^{*}$ Jing Yang, ${ }^{\dagger}$ Lina Song, ${ }^{*}$ \\ Jing Feng, ${ }^{*}$ Dongling Yang, ${ }^{*}$ Zhihai Qin, ${ }^{*}$ and Xiyun Yan*
}

\begin{abstract}
From the Key Laboratory of Protein and Peptide Pharmaceuticals, Center for Infection and Immunity, and the Chinese Academy of Sciences-University of Tokyo Joint Laboratory of Structural Virology and Immunology, Institute of Biophysics, Chinese Academy of Sciences, * Beijing; and the Department of Gastroenterology, ${ }^{\dagger}$ Chinese PLA General Hospital, Beijing, China
\end{abstract}

\begin{abstract}
CME Accreditation Statement: This activity ("ASIP 2014 AJP CME Program in Pathogenesis") has been planned and implemented in accordance with the Essential Areas and policies of the Accreditation Council for Continuing Medical Education (ACCME) through the joint sponsorship of the American Society for Clinical Pathology (ASCP) and the American Society for Investigative Pathology (ASIP). ASCP is accredited by the ACCME to provide continuing medical education for physicians.
\end{abstract}

The ASCP designates this journal-based CME activity (“ASIP 2014 AJP CME Program in Pathogenesis") for a maximum of 48 AMA PRA Category 1 Credit(s) ${ }^{\mathrm{TM}}$. Physicians should only claim credit commensurate with the extent of their participation in the activity.

CME Disclosures: The authors of this article and the planning committee members and staff have no relevant financial relationships with commercial interests to disclose.

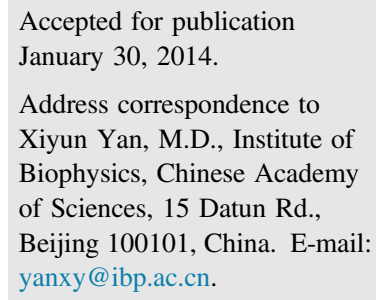

\begin{abstract}
Recently, enhanced CD146 expression was reported on endothelial cells in intestinal biopsies from patients with inflammatory bowel disease. However, the underlying mechanism remains unknown. Here, we found that overexpressed endothelial CD146 promoted the inflammatory responses in inflammatory bowel disease, which further potentiated the occurrence of colitis-associated colorectal carcinogenesis. Eliminating endothelial CD146 by conditional knockout significantly ameliorated the severity of inflammation in two different murine models of colitis, and decreased tumor incidence and tumor progression in a murine model of colitis-associated colorectal carcinogenesis. Mechanistic study showed that cytokine tumor necrosis factor- $\alpha$ (TNF- $\alpha$ ) up-regulated the expression of endothelial CD146 through NF- $\kappa B$ transactivation. In turn, the enhanced endothelial CD146 expression promoted both angiogenesis and proinflammatory leukocyte extravasations, contributing to inflammation. Using an anti-CD146 antibody, AA98, alone or together with an anti-TNF- $\alpha$ antibody significantly attenuated colitis and prevented colitis-associated colorectal carcinogenesis in mice. Our study provides the first evidence that CD146 plays a dual role on endothelium, facilitating leukocyte extravasations and angiogenesis, thus promoting inflammation. This finding not only reveals the function and regulating mechanism of CD146 in inflammatory bowel disease, but also provides a promising therapeutic strategy for treating inflammatory bowel disease and preventing colitis-associated colorectal carcinogenesis. (Am J Pathol 2014, 184: 1604-1616; http://dx.doi.org/10.1016/j.ajpath.2014.01.031)
\end{abstract}

Evidence is accumulating that chronic inflammation contributes to carcinogenesis, including gastrointestinal cancers, lung cancer, and prostate cancer. ${ }^{1}$ Chronic colitis-associated colorectal carcinogenesis $(\mathrm{CAC})^{2}$ is a typical model to study inflammation-associated carcinogenesis. Ulcerative colitis (UC), a major form of inflammatory bowel disease (IBD), is characterized by a long-lasting cycle of remission and exacerbations of ulceration of bowels, abdominal pain, diarrhea, bloody stool, and other systemic symptoms. ${ }^{3}$ It is reported that patients suffering from UC for more than 10 years are 6 to 10 times more susceptible to develop colorectal cancer than the general population. ${ }^{4}$ Furthermore, both the severity and the duration of the chronic IBD significantly correlate with the

\footnotetext{
Supported in part by grants from the National Natural Science Foundation of China (91329102, 81272409, 31300729, 81371330, and 81371025) and the National Basic Research Program of China (973 program) (2011CB915502).

S.X. and Y.L. contributed equally to this work.

Disclosures: None declared.
} 
risk of colorectal cancer. ${ }^{5}$ Although inflammatory cytokines that mediated signaling in linking IBD and CAC were recently reported, such as tumor necrosis factor- $\alpha$ (TNF- $\alpha)$ /inhibitor of nuclear factor kappa-B kinase- $\beta$ (IKK- $\beta$ ) $/ \mathrm{NF}-\kappa \mathrm{B}^{6,7}$ and vascular endothelial growth factor (VEGF)/VEGF receptor (VEGFR), ${ }^{8}$ the underlying mechanisms need to be further explored.

The occurrence and progression of CAC are believed to be an orchestrated process involving the complex interplay between premalignant epithelial cells and the inflammatory environment, where blood vessel formation and inflammatory immune cell infiltration may play fundamental roles. Therefore, targeting angiogenesis ${ }^{9}$ and lymphocyte infiltration ${ }^{10-13}$ become promising therapeutic strategy to alleviate inflammation. Ideally, a simultaneous blockage of lymphocyte infiltration and angiogenesis by targeting one molecule would be more efficient for modulating inflammation and preventing CAC.

CD146, an adhesion molecule belonging to the immunoglobulin superfamily, has been reported to be expressed on certain cancer cells, endothelial cells, and some subpopulations of leukocyte cells. ${ }^{14}$ Our previous studies have identified that CD146 plays a key role in tumorassociated angiogenesis, ${ }^{15-19}$ as well as in tumor metastasis. $^{20,21}$ The CD146 antibody AA98 inhibits tumor angiogenesis. ${ }^{22}$ Tsiolakidou et $\mathrm{al}^{23}$ and Bardin et $\mathrm{al}^{24}$ respectively, reported increased expression of CD146 in patients with IBD. However, the function of CD146 and its regulatory mechanisms in IBD remain unknown. There are also clinical observations reporting that CD146 expression was associated with other inflammatory diseases such as rheumatoid arthritis, chronic renal failure, and diabetes through mechanisms yet unclear. ${ }^{25-27}$ Therefore, it is of great interest to study how CD146 functions in inflammatory diseases, and more importantly, its role in chronic inflammation-associated carcinogenesis.

In this study, we found that endothelial CD146 plays important roles in the progression of IBD and CAC. CD146 was overexpressed on the endothelial cells in colitis and CAC model mice, but not on epithelial cells and tumor cells. Eliminating endothelial CD146 by conditional knockout or blocking CD146 by antibody AA98 significantly alleviated the disease severity in murine models of colitis and decreased tumor incidence in a murine model of CAC. Mechanistic study revealed that TNF- $\alpha$ and IL1- $\beta$ strongly induced CD146 expression on endothelial cells by direct NF- $\kappa \mathrm{B}$ transactivation. Up-regulated endothelial CD146 played a dual function in inflammation, that is, promoting angiogenesis and recruiting lymphocytes, especially proinflammatory Th1 and Th17 cells. This, in turn, results in a vicious cycle of chronic inflammation, which promotes the occurrence of CAC. Our study suggests that CD146 is an important molecule involved in inflammation and carcinogenesis, which can be a therapeutic target in the treatment of IBD and prevention of CAC.

\section{Materials and Methods}

\section{Antibodies and Reagents}

The following antibodies were used in this study: antiCD146 monoclonal antibody AA98, ${ }^{22,28}$ anti-mTNF- $\alpha$ monoclonal antibody ${\mathrm{V} 1 \mathrm{q}^{29}}^{29}$ were used as functional blocking antibody in animal experiments. Anti-p-Akt, antip-p65, anti-p-MAPKAPK-2, anti-p65 (Cell Signaling Technology, Danvers, MA), anti-glyceraldehyde3-phosphate dehydrogenase (GAPDH) (Santa Cruz Biotechnology, Santa Cruz, CA), antibody AA98, and horseradish peroxidase-conjugated anti-mouse and antirabbit secondary antibodies (GE Healthcare, Chalfont St Giles, UK) were used in the Western blot assays. Antihuman and anti-mouse CD31 (Cymbus Biotechnology, Chandlers Ford, UK), anti-mouse CD146 (clone 9F1), antimouse CD45, anti-mouse CD4 (BioLegend, San Diego, $\mathrm{CA}$ ), anti- $\beta$-catenin (BD Biosciences, San Jose, CA), antimouse IL17 (clone 17F3; eBioscience, San Diego, CA), anti-Ki-67 (clone M-19; Santa Cruz Biotechnology), and DAPI (AppliChem, Darmstadt, Germany) were used in immunohistochemistry or immunofluorescence analysis. Anti-p65 polyclonal antibody and Isotype-matched rabbit IgG (Abcam) were used in the chromatin immunoprecipitation (ChIP) assay. Phycoerythrin (PE)-conjugated AA98 (labeled by Tianjin Sungene Biotech, Tianjin, China), fluorescein isothiocyanate-conjugated anti-mouse IL17A (clone 17F3), and allophycocyanin (APC)-conjugated anti-mouse CD4 (clone GK1.5) (Tianjin Sungene Biotech), PerCP cy5.5-conjugated anti-mouse $\mathrm{CD} 3$, and PE-conjugated antimouse interferon- $\gamma(\mathrm{IFN}-\gamma)$ (eBioscience) were used in flow cytometry assays. Anti-CD146 siRNA and control green fluorescent protein (GFP) siRNA were synthesized by Invitrogen (Carlsbad, CA) using sequences as previously reported. ${ }^{30}$ P65 siRNA was purchased from Santa Cruz Biotechnology. The recombinant cytokines TNF- $\alpha$, IFN- $\gamma$, IL1- $\beta$, and IL6 were purchased from PeproTech (Rocky Hill, NJ). Phytohaemagglutinin-P and lipopolysaccharide (LPS) were obtained from Sigma-Aldrich (St. Louis, MO). Dextran sulfate sodium (DSS) (mol. wt. 36,000 to 50,000) and azoxymethane (AOM) were obtained from MP Biomedicals (Santa Ana, CA) and Sigma-Aldrich, respectively. A BD Cytometric Bead Array kit for flow cytometry-based detection of serum cytokines was purchased from BD Biosciences. A TUNEL in situ apoptosis detection kit was purchased from TaKaRa Bio (Otsu, Japan). Human colon disease spectrum tissue microarray (BC05002) was bought from US Biomax (Rockville, MD).

\section{Cell Culture and Animals}

Human umbilical vein endothelial cells (HUVECs) were obtained from CellSystems Biotechnologie Vertrieb (St. Katharinen, Germany). Mouse endothelioma cell line used was sEnd.1. Human monocyte cell-line THP-1 cells were 
obtained from ATCC (Manassas, VA). These cells were cultured in RPMI 1640 medium containing $10 \%$ fetal calf serum at $37^{\circ} \mathrm{C}$ with $5 \% \mathrm{CO}_{2}$.

All animal experiments were performed in compliance with the Guidelines for the Care and Use of Laboratory Animals and were approved by the Biomedical Research Ethics Committee of the Institute of Biophysics, Chinese Academy of Sciences. C57BL/6J mice were obtained from the Animal Center of the Chinese Academy of Medical Science, Beijing. $\mathrm{Tek}^{+/ \mathrm{Cre}} \mathrm{CD} 146^{\text {floxedffloxed }}$ mice were generated using a Cre/ loxP recombination system. One loxP site was inserted in the intron before the promoter region of the CD146 (MCAM) gene, and one $\operatorname{lox} P$ site was inserted in the intron after the first exon. The $\mathrm{Cre}$ gene was driven by the promoter Tek of the Tie 2 gene, which is expressed specifically on endothelial cells. $\mathrm{Tek}^{+/+} \mathrm{CD} 146^{\text {floxedffloxed }}$ mice were backcrossed to mice on a C57BL/6J background for a minimum of nine generations. $\mathrm{Tek}^{+/ \mathrm{Cre}} \mathrm{CD} 146^{+/+}$mice were then crossed with $T e k^{+/+} C D 146^{\text {floxed/floxed }}$ mice. The $\mathrm{F}_{1}$ mice with genotype $\mathrm{Tek}^{+/ \mathrm{Cre}} \mathrm{CD} 146^{+/ \text {floxed }}$ were crossed with $\mathrm{Tek}^{+/+}$ CD146 floxedffloxed mice to obtain $\mathrm{Te}^{+/ C r e} \mathrm{CD} 146^{\text {floxedffloxed }}$ mice (named CD146 ${ }^{\mathrm{EC}-\mathrm{KO}}$ ). $\mathrm{Te}^{+/+} \mathrm{CD} 146^{\text {floxedffloxed }}$ [named wild-type (WT)] mice were used as a control. ${ }^{19}$ Genotyping of each generation was performed using PCR. The complete absence of CD146 from the blood vessel endothelial cells was confirmed using immunofluorescence (Supplemental Figure S1), as we previously reported. ${ }^{31}$

\section{Colitis, CAC Induction, and Treatment of Mice}

Pathogen-free 8-week-old female C57BL/6J mice, $\mathrm{CD} 146^{\mathrm{EC}-\mathrm{KO}}$ mice, and their counterpart WT littermates were randomly grouped into 8 to 10 mice/group. These mice were housed under specific pathogen-free conditions with free access to food and water during the course of the experiments. For the DSS-induced acute colitis model, 3\% DSS was given in the drinking water over 5 days, followed by normal water for 5 days. In the antibody preventive treatment experiment, mice were injected i.p. with AA98 or control murine $\mathrm{IgG}(\mathrm{mIgG})$ at a dose of $10 \mathrm{mg} / \mathrm{kg}$ body weight at day 1 , day 3 , day 5 , and day 7 . For the chronic colitis therapeutic model, 2\% DSS was given for 5 days followed by normal water for 7 days. This cycle was repeated three times. Starting at day 30, after the onset of disease, mice were injected i.p. with $10 \mathrm{mg} / \mathrm{kg}$ body weight AA98, $1 \mathrm{mg} / \mathrm{kg}$ body weight V1q, or their combination every other day for four times. The induction of colitis using TNBS (2,4,6-trinitro benzene sulfonic acid; Sigma-Aldrich) was performed according to the protocol previously reported ${ }^{32}$ In brief, the mice were first presensitized by $150 \mu \mathrm{L}$ of the TNBS presensitization solution (acetone and olive oil were mixed in a $4: 1$ volume ratio, and then four volumes of acetone/olive oil were mixed with one volume of 5\% TNBS solution) on their shaved skin. Seven days later, mice were lightly anesthetized and then administrated $150 \mu \mathrm{L}$ of TNBS solution (one volume of 5\% TNBS solution was mixed with one volume of absolute ethanol) in the colon lumen via a 3.5-F catheter inserted into the colon $4 \mathrm{~cm}$ proximal to the anus. To ensure distribution of the haptenating agent within the entire colon and cecum, mice were held in a vertical position for 60 seconds. Control mice were administrated $150 \mu \mathrm{L}$ of $50 \%$ ethanol solution using the same technique. The disease activity index (DAI) was evaluated by scoring the level of body weight loss, stool guaiac positivity, or gross bleeding, and stool consistency (0 to 4 for each aspect for a combination score up to 12), by an investigator blinded to the protocol (H.D.), as previously reported. ${ }^{33}$ For the CAC model, $\mathrm{CD} 146^{\mathrm{EC}-\mathrm{KO}}$ and their WT counterpart, or C57BL/6J mice were injected i.p. with $12.5 \mathrm{mg} / \mathrm{kg}$ AOM. Five days afterwards, mice were treated with the following regimen: three cycles of $2.0 \%$ DSS in drinking water for 5 days, followed by regular water for 14 days to induce chronic colitis. For antibody treatment, AA98 or $\mathrm{mIgG}$ was injected i.p. at 10 $\mathrm{mg} / \mathrm{kg}$ body weight every other day for three times during each DSS feeding period.

\section{Histopathological and Immunohistochemical Analysis of Mouse Colon Sections}

After sacrifice, the colon was removed and cleaned. A 0.5$\mathrm{cm}$ section of the distal third of the colon was collected and stored at $-80^{\circ} \mathrm{C}$ for mRNA isolation. The rest of the colon was rolled as a Swiss roll, ${ }^{34}$ fixed in $10 \%$ formalin neutral buffer solution. Paraffin-embedded sections were cut at $5 \mu \mathrm{m}$ and stained with $\mathrm{H} \& \mathrm{E}$ solution. Histological scores were evaluated by two independent investigators (H.D. and D.L.), blinded to the source of treatment, as follows ${ }^{33}$ : Epithelium scores 0 , normal morphology; 1 , loss of goblet cells; 2 , loss of goblet cells in large areas; 3, loss of crypts; 4, loss of crypts in large areas. Infiltration scores: 0, no infiltrate; 1 , infiltrate around crypt basis; 2 , infiltrate reaching to $\mathrm{L}$. muscularis mucosae; 3 , extensive infiltration reaching the muscularis mucosae and thickening of the mucosa; 4 , infiltration of the L. submucosa. The total histological score represents the sum of the epithelium and infiltration score, and ranges from 0 to 8 .

These sections were further analyzed by immunohistochemistry or immunofluorescence analysis for CD146, CD31 or CD45, CD4. Leukocyte infiltration and blood vessel density were quantified in at least five random areas per section, as previously reported. ${ }^{35}$

\section{Isolation and Subsequent Analysis of Murine Lamina Propria Lymphocyte}

According to the method of Weigmann et al, ${ }^{36}$ mouse colons were removed and cleaned. Colons were first predigested with $5 \mathrm{mmol} / \mathrm{L}$ EDTA and $1 \mathrm{mmol} / \mathrm{L}$ dithiothreitol. Intraepithelial lymphocytes were discarded. The colons were then digested with $0.05 \mathrm{~g}$ of collagenase D (Roche, Basel, Switzerland), $0.05 \mathrm{~g}$ of DNase I (Sigma-Aldrich). Lamina propria mononuclear cells were isolated on a 40/80 Percoll gradient. Lamina propria mononuclear cells were then stimulated with $1 \mathrm{ng} / \mathrm{mL}$ phorbol-12-myristate-13-acetate and $500 \mathrm{ng} / \mathrm{mL}$ 
ionomycin (Sigma-Aldrich), harvested and stained with anti-CD3-Percypt cy5.5, anti-CD4-APC, anti-IL17AFITC, or anti-IFN- $\gamma-$ PE (e-Bioscience). Cells were analyzed using BD LSRFortessa (BD Biosciences).

\section{Real-Time RT-PCR for Analyzing mRNA Expression Levels}

Total RNA was extracted from $30 \mathrm{mg}$ of colon tissues with Trizol reagent (Invitrogen). RNA $(2 \mu \mathrm{g})$ was reverse transcribed into cDNA by random primers. Real-time PCR analysis was performed on a Corbett 6200 using SYBR Green PCR mix (Toyobo Co., Osaka, Japan). Threshold cycle (Ct) values of GAPDH were subtracted from $\mathrm{Ct}$ values of the genes of interest $(\Delta \mathrm{Ct})$. $\Delta \mathrm{Ct}$ values of mice under different treatments were compared with $\Delta \mathrm{Ct}$ values of untreated mice (naive). The primers for cytokines were purchased from Qiagen (QuantiTect Primer Assays; Valencia, CA), and primers for mouse CD146 and GAPDH were synthesized by Invitrogen using the following sequence (sense; antisense): mCD146: 5'TCAATGGTTCGGCAACTGAATGGA-3'; 5'-GGGAGTTGGAGGCTGTACACTCTGCACC-3'; mGAPDH: 5'-CTCACTCAAGATTGTCAGCA-3'; 5'-GTCTTCTGGGTGGCAGTGAT-3'.

\section{ChIP Assays}

HUVEC cells were treated with $40 \mathrm{ng} / \mathrm{mL}$ TNF- $\alpha$ for 12 hours and fixed for 10 minutes in $1 \%$ formaldehyde at room temperature. Chromatin was then sheared to 300 to $1000 \mathrm{bp}$ in length by sonication. Immunoprecipitation was performed with a rabbit anti-p65 polyclonal antibody or control rabbit IgG. Recovered DNA was quantified by PCR and normalized with input DNA. The primers for putative NF- $\kappa \mathrm{B}$ binding sites were: NF-621 sense, 5'-GACTTGCAGGAGCTTGCG-

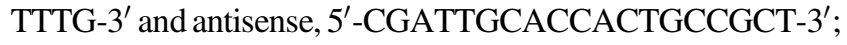
and NF-420 sense, $5^{\prime}$-GCGGCAGCGGCAGTGGTG- $3^{\prime}$ and antisense, $5^{\prime}$-GGTAGTGACAGGTGTCTCGGG-3' ${ }^{\prime}$. GAPDH sense, 5'-CGGAGTCAACGGATTTGGTCGTAT-3', antisense 5'-AGCCTTCTCCATGGTGGTGAAGAC-3' was used as control. The PCR products were separated on $1.5 \%$ agarose gels.

\section{Dural Luciferase Reporter Assay}

A 2-kb CD146 promoter region was amplified from genomic DNA of HUVEC cells and cloned upstream of firefly luciferase in the pGL3 plasmid (Promega, Madison, WI). The mutants of putative NF- $\kappa B$ binding sites of CD146 promoter regions were generated by PCR and confirmed by sequencing. The pGL3 vectors containing WT or mutant CD146 promoter were then transfected into HUVECs, together with pRLTK containing the Renilla luciferase reporter gene and the control empty plasmid. Twelve hours after transfection, cells were treated with $40 \mathrm{ng} / \mathrm{mL}$ TNF- $\alpha$ for 24 hours. Firefly and Renilla luciferase activities were then measured with the Dual-Luc Assay Kit (Promega).

\section{Tube Formation Assay}

Five experimental groups of HUVECs were prepared with different treatments: mock group (transfected with GFP siRNA and stimulated with PBS, adding $50 \mu \mathrm{g} / \mathrm{mL} \mathrm{mIgG}$ right before performing the following experiments), TNF- $\alpha$ stimulation group (transfected with GFP siRNA and stimulated with $\mathrm{TNF}-\alpha$, adding $\mathrm{mIgG}$ ), restoration group (transfected with CD146 siRNA and stimulated with TNF- $\alpha$, adding mIgG), blockage group (blockage of NF- $\kappa B$ pathway by BAY11-7082 and stimulated with TNF- $\alpha$, adding $\mathrm{mIgG}$ ), and functional antibody AA98 block group (transfected with GFP siRNA and stimulated with TNF- $\alpha$, adding $50 \mu \mathrm{g} / \mathrm{mL}$ AA98). The relative ratio of TNF- $\alpha$ and CD146 siRNA concentration was adjusted to restore CD146 to its background level of untreated HUVECs as determined by Western blot. Matrigel (BD Biosciences) was thawed at $4^{\circ} \mathrm{C}$ overnight, and each well of a pre-chilled 96-well plate was coated with $50 \mu \mathrm{L}$ of Matrigel and incubated at $37^{\circ} \mathrm{C}$ for 2 hours. As described above, the differentially treated HUVECs were harvested, washed, and then suspended in RPMI 1640 medium containing 10\% fetal bovine serum, then added into Matrigel-coated wells. After 12 hours of incubation at $37^{\circ} \mathrm{C}$, the cells were observed under a confocal laser scanning microscope (FV500; Olympus, Tokyo, Japan). Endothelial cell tube formation was assessed by endothelial cord branch points and vessel length.

\section{Leukocyte Adhesion and Transendothelium Migration Assays}

As described above, HUVECs of different treatment were seeded into a 96-well plate or the upper chamber of transwell plates (96-well insert; pore size $8 \mu \mathrm{m}$, Corning Costar; Corning, Corning, NY) for 10,000 cells per well. Subsequently, cells were incubated for 24 hours, stimulated by $40 \mathrm{ng} / \mathrm{mL} \mathrm{TNF}-\alpha$ or PBS. Thirty thousand fresh isolated peripheral mononuclear cells (PBMCs) or THP-1 cells/well were stained with carboxyfluorescein succinimidyl ester and added to the plate or upper chamber. For the adhesion assay, after incubation for 1 hour, wells were washed three times with $0.2 \mathrm{~mL}$ of warmed assay medium to remove nonadherent leukocytes. The adhered leukocyte were harvested and analyzed by flow cytometry. For the transmigration assay, the leukocytes were allowed to migrate through the endothelial monolayer for 12 hours. The transmigrated cells in lower chamber were collected and analyzed by flow cytometry.

\section{In Vitro T-Cell Differentiation}

$\mathrm{CD}^{+}{ }^{+} \mathrm{T}$ cells isolated using a CD4 ${ }^{+} \mathrm{T}$-cell Isolation Kit II (Miltenyi Biotec, Bergisch Gladbach, Germany) from 
spleen and lymph nodes were activated with plate-bound $3 \mu \mathrm{g} / \mathrm{mL}$ anti-CD3 (145-2C11; BD Biosciences) and $3 \mu \mathrm{g} / \mathrm{mL}$ CD28 (37.51; BD Biosciences). The following Th17 culture condition was used: $0.5 \mathrm{ng} / \mathrm{mL}$ TGF- $\beta$ (R\&D Systems, Minneapolis, MI), $10 \mathrm{ng} / \mathrm{mL}$ IL-6 (R\&D Systems), $10 \mathrm{ng} / \mathrm{mL}$ IL-1 $\beta$ (R\&D Systems), $10 \mathrm{ng} / \mathrm{mL}$ IL-21 (R\&D Systems), $10 \mu \mathrm{g} / \mathrm{mL}$ anti-IFN- $\gamma$ (XMG1.2; BD Biosciences), $10 \mu \mathrm{g} / \mathrm{mL}$ anti-IL-12p40, and $10 \mu \mathrm{g} / \mathrm{mL}$ antiIL-4 (11B.11; National Cancer Institute, Frederick, MD). The following Th1 culture condition was used: $50 \mathrm{U} / \mathrm{mL}$ IL-2, $10 \mu \mathrm{ng} / \mathrm{mL}$ IL-12, $10 \mu \mathrm{g} / \mathrm{mL}$ anti-IL-4 (11B.11; National Cancer Institute). The following regulatory $\mathrm{T}$ cell (Treg) culture condition was used: $5 \mathrm{ng} / \mathrm{mL}$ TGF- $\beta, 50 \mathrm{U} / \mathrm{mL}$ IL-2 (National Cancer Institute), $10 \mu \mathrm{g} / \mathrm{mL}$ anti-IL-4, $10 \mu \mathrm{g} / \mathrm{mL}$ anti-IL-12p40, $10 \mu \mathrm{g} / \mathrm{mL}$ anti-IFN- $\gamma$. Th0 cells were maintained with $50 \mathrm{U} / \mathrm{mL}$ IL-2. These T cells were activated for 4 days before being used for transmigration assays.

\section{Statistical Analysis}

The results are presented as means \pm SEM. Differences between groups were calculated for significance by one-way or two-way analysis of variance with a Tukey test using GraphPad Prism software version 5 (GraphPad Software, La Jolla, CA). For statistical analysis of DAI, two-tailed paired Student's $t$-test was used. A $P$ value $<0.05$ was considered significant. All of the experiments were repeated at least three times independently, and representative data were shown.

\section{Results}

\section{Colitis Severity Is Reduced in Endothelial CD146 Knockout Mice}

It has been reported that CD146 expression is increased on blood vessels of IBD patients by an unknown mechanism. ${ }^{23,24}$ Consistently, we found both increased endothelial CD146 expression and enhanced angiogenesis in colon tissues from DSS-induced colitis model mice; however, no epithelial CD146 expression was observed (Figure 1A). To investigate the function of endothelial CD146 in inflammation during colitis, we compared the susceptibility of the conditional endothelial cell CD146 knockout mice $\left(\mathrm{CD} 146^{\mathrm{EC}-\mathrm{KO}}\right)$ and WT mice to DSS-induced acute colitis. In the $\mathrm{CD} 146^{\mathrm{EC}-\mathrm{KO}}$ mice, we confirmed the depletion of CD146 in vascular endothelial cells (Supplemental Figure S1) but not in other CD146-expressing cells such as hematopoietic stem cells $\left(\mathrm{CD} 117^{+} \mathrm{CD} 146^{+}\right)$and $\mathrm{CD} 146^{+}$lymphocytes, as we reported previously. ${ }^{31}$ In addition, no significant differences in colon histology, colon cytokine mRNA levels, and lymphocyte subpopulations were observed between naive (nontreated) CD146 ${ }^{\mathrm{EC}-\mathrm{KO}}$ mice and WT mice (Supplemental Figure S2). When DSS induction was performed, deletion of CD146 in endothelial cells markedly dampened disease severity, including weight loss, occult and rectal bleeding, and diarrhea of mice, as shown by the DAI in Figure 1B.
Necropsy of mice at day 9 revealed alleviated edema and shortening of the colons in DSS-fed CD146 ${ }^{\mathrm{EC}-\mathrm{KO}}$ mice compared with WT mice (data not shown). In addition, less severe epithelial damage and lymphocyte infiltration were found in DSS-induced CD146 ${ }^{\mathrm{EC}-\mathrm{KO}}$ mice by histological examination of colonic sections (Figure 1B).

Using CD31 and CD45 marking blood vessel endothelium and pan-lymphocytic cells, respectively, we noted decreases of both vessel density and leukocyte infiltration in colon tissue of CD146 ${ }^{\mathrm{EC}-\mathrm{KO}}$ mice compared with WT mice (Figure 1, C and D). Because Th1 and Th17 are two major proinflammatory lymphocytes that have been implicated in IBD, ${ }^{37}$ we investigated the possibility that endothelial CD146 was involved in recruiting these lymphocytes to sites of active inflammation. The infiltrated lymphocytes in the lamina propria of DSS-treated CD146 ${ }^{\mathrm{EC}-\mathrm{KO}}$ and WT mice were isolated and analyzed. We found fewer $\mathrm{CD} 4{ }^{+}$lymphocytes and a lower percentage of Th1 and Th17 cells present in the colon of CD146 ${ }^{\mathrm{EC}-\mathrm{KO}}$ mice than that of WT mice (Figure 1E). Also, the $\mathrm{IFN}-\gamma^{+} \mathrm{IL} 17^{+}$double-positive cells were reduced (Supplemental Figure S3). In addition, mRNA levels of cytokines in the colon tissue were measured to evaluate the inflammation status during colitis. The expression of major proinflammatory cytokines, including TNF- $\alpha$, IL1- $\beta$, and IL6, were all reduced in CD146 ${ }^{\mathrm{EC}-\mathrm{KO}}$ mice (Figure 1F).

Furthermore, a TNBS acid-induced colitis model was used to confirm the possible role of endothelial CD146 in mediating lymphocyte infiltration, because TNBS-induced colitis was characterized by a predominant Th1-mediated immune response. ${ }^{38,39}$ Colitis severity was significantly ameliorated in TNBS-induced CD146 ${ }^{\mathrm{EC}-\mathrm{KO}}$ mice, compared with induced WT mice (Supplemental Figure S4). The infiltration of $\mathrm{CD}^{+}$lymphocyte, as detected by immunofluorescence and flow cytometry, was markedly reduced in the $\mathrm{CD} 146^{\mathrm{EC}-\mathrm{KO}}$ model mice. We also found reduced infiltration of Th1 and Th17 cells in the colons of CD146 ${ }^{\mathrm{EC}-\mathrm{KO}}$ model mice, compared with that of WT model mice.

Taken together, these data indicate that endothelial CD146 plays a crucial role in the pathogenesis of colitis by promoting inflammation.

\section{Eliminating CD146 Inhibits Colitis-Associated Colorectal Carcinogenesis}

Chronic inflammation contributes to carcinogenesis. To determine whether the role of CD146 in inflammation is of importance in CAC, we evaluated the susceptibility of WT and $\mathrm{CD} 146^{\mathrm{EC}-\mathrm{KO}}$ mice to AOM-DSS-induced CAC (Figure 2A). During the course of DSS treatment, profound body weight loss and bloody diarrhea were observed in WT mice, compared with much milder symptoms in CD146 ${ }^{\mathrm{EC}-\mathrm{KO}}$ mice (data not shown). When mice were sacrificed at day 62 , reduced tumor incidence and smaller tumor volume were observed in $\mathrm{CD} 146^{\mathrm{EC}-\mathrm{KO}}$ mice compared with WT mice (Figure 2, B-D). Immunofluorescence analysis revealed lower blood vessel density and a decreased level of $\mathrm{CD} 4^{+}$ 


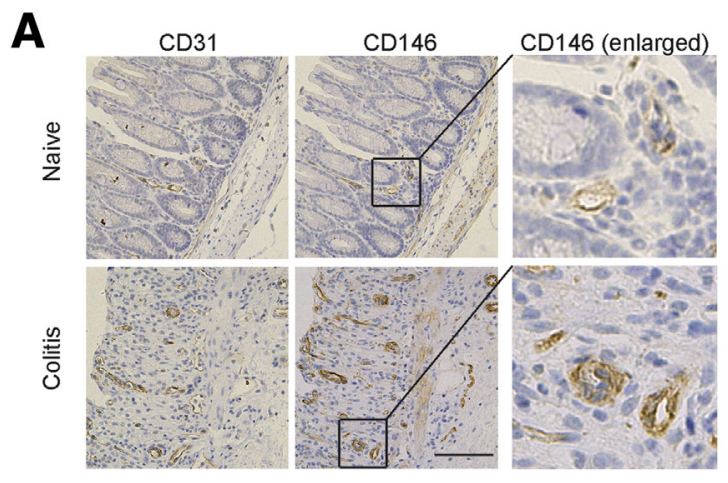

B

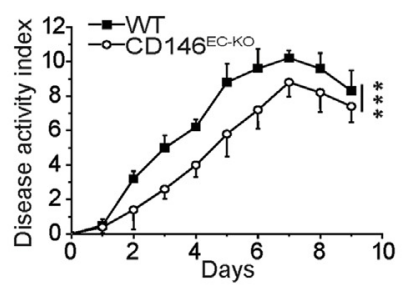

C

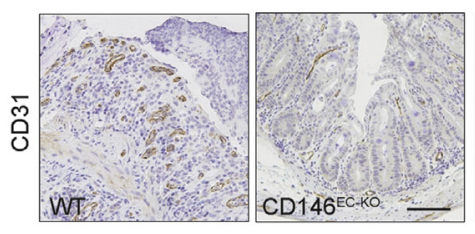

D

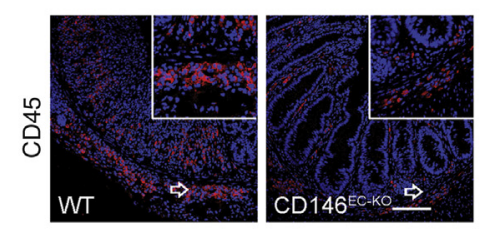

\section{E}

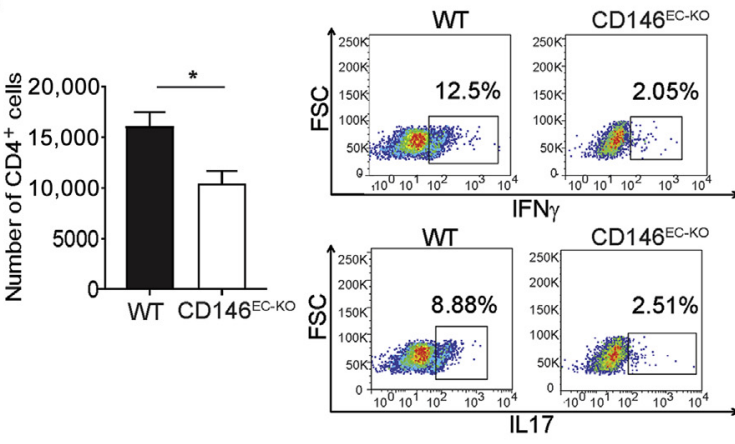

F
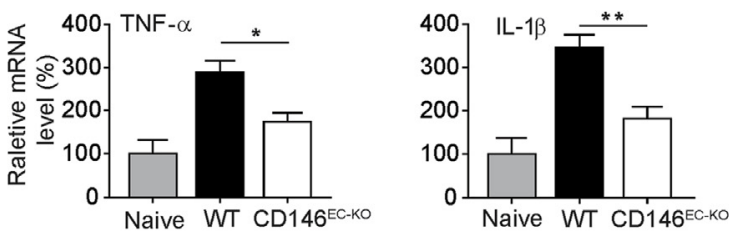
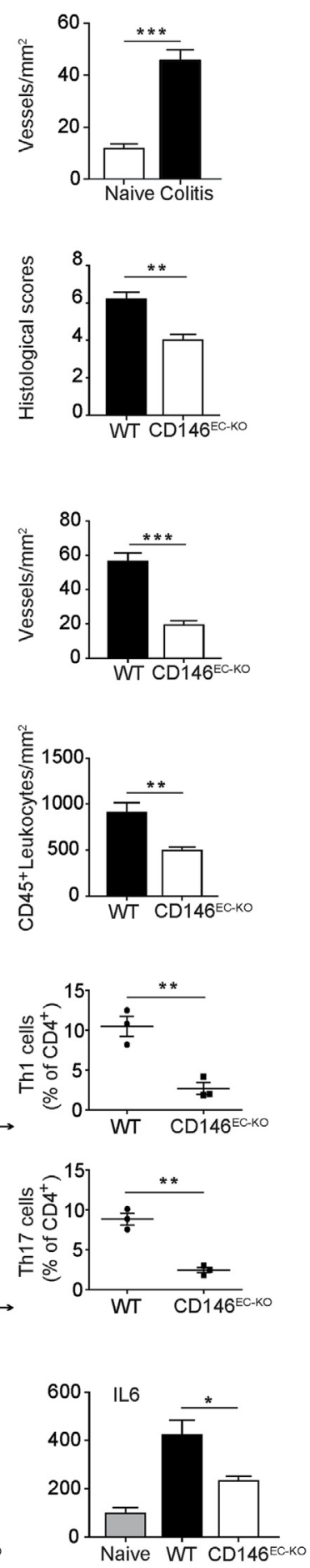

Figure $1 \quad \mathrm{CD} 146^{\mathrm{EC}-\mathrm{KO}}$ mice develop less severe colitis than WT mice in a DSS-induced colitis model. A: Representative images of analysis of CD146 expression and blood vessel density in colons of nontreated mice (naive) or DSS-induced colitis mice (colitis) by immunohistochemistry. CD31 was used as an endothelial cell marker. Blood vessel density was quantified as vessels per $\mathrm{mm}^{2}$ as shown in the bar graph. B: Comparison of disease activity index (DAI) and histological scores of DSSinduced colitis between CD146 $6^{\mathrm{EC}-\mathrm{KO}}$ and WT mice. C: Representative images of immunohistochemical analysis for blood vessel density in colons of CD146 ${ }^{\mathrm{EC}-\mathrm{KO}}$ and WT mice with DSS-induced colitis. CD31 was used as an endothelial cell marker. Blood vessel density was quantified as vessels per $\mathrm{mm}^{2}$ as shown in the bar graph. D: Representative images of immunofluorescence detection of $\mathrm{CD} 5^{+}$leukocytes (red) infiltration into the colons of CD146 ${ }^{\mathrm{EC}-\mathrm{KO}}$ and WT mice with DSS-induced colitis. DAPI (blue) was used for staining cell nuclei. Enlarged images of regions indicated by arrows were shown on the upper right of each image. The bar graph shows quantification of infiltration. E: Flow cytometry analysis of infiltrated lymphocytes isolated from the colons of the CD146 $6^{\mathrm{EC}-\mathrm{KO}}$ and WT mice with DSS-induced colitis. The absolute number of $\mathrm{CD}^{+}$lymphocyte and the portion of Th1 and Th17 lymphocyte are shown. IFN- $\gamma$ or IL17 were analyzed to represent Th1 or Th17 lymphocytes. Each dot represents the value of a combined sample from two mice in the same group. F: Analysis of the relative mRNA levels of TNF- $\alpha$, IL1- $\beta$, and IL6 in the colon tissues of CD146 $6^{\mathrm{EC}-\mathrm{KO}}$ and WT mice with DSS-induced colitis, by real-time RT-PCR and normalization to GAPDH. For each cytokine, the mRNA level of nontreated WT mice (naive) was set as $100 \%$. ${ }^{*} P<0.05,{ }^{*} P<0.01$, and $* * * P<0.001 . n=3$ per group ( $\mathbf{A}$ and $\mathbf{C}-\mathbf{F})$; $n=6$ (B). Scale bars: $100 \mu \mathrm{m}$ (A); $200 \mu \mathrm{m}$ (C and D). leukocyte infiltration in the tumor regions of $\mathrm{CD} 146^{\mathrm{EC}-\mathrm{KO}}$ mice (Figure 2, E and F). Moreover, significantly decreased mRNA level of TNF- $\alpha$, IL1- $\beta$, IFN- $\gamma$, and IL6 was found in colon samples from $\mathrm{CD} 146^{\mathrm{EC}-\mathrm{KO}}$ mice compared with those from treated WT mice (Figure 2G). Also, COX-2, whose expression is pivotal in $\mathrm{CAC},{ }^{40}$ was significantly reduced in $\mathrm{CD} 146^{\mathrm{EC}-\mathrm{KO}}$ mice compared to WT mice. Consistently, by analyzing the cytokine concentration present in serum, we 
A Day 0 Day 5 2.0\% DSs for 5 days then water for 14 days

B

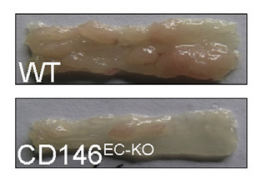

C
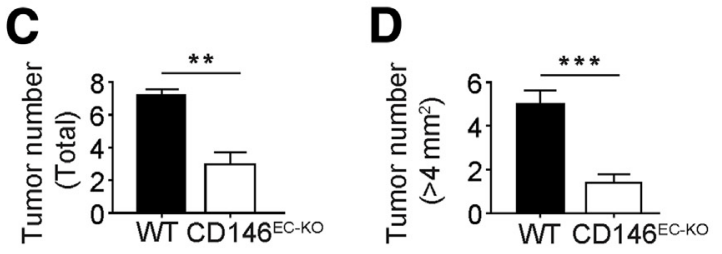

E
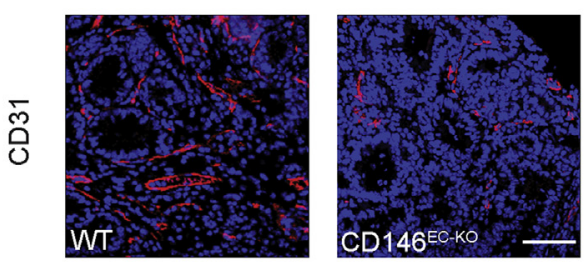

$\mathbf{F}$
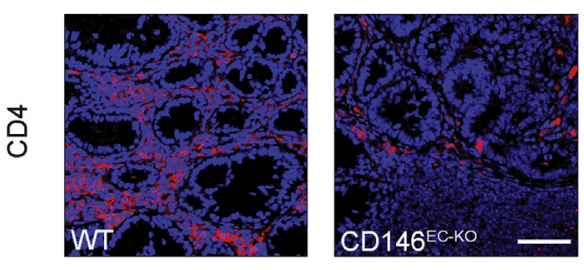

G

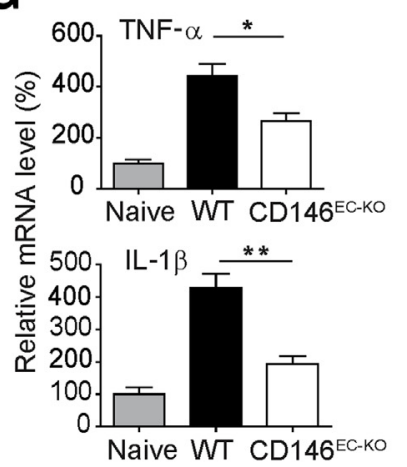

1500

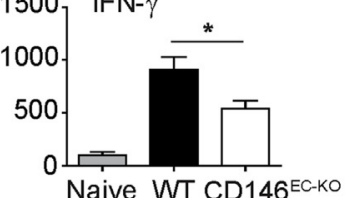

Naive WT CD146EC-Ko

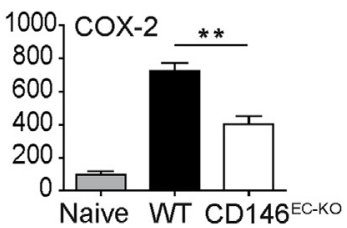

Figure 2 CD146 potentiates the occurrence of colitis-associated colorectal carcinogenesis by facilitating inflammation. A: Schematic overview of experimental CAC model using $\mathrm{CD} 146^{\mathrm{EC}-\mathrm{KO}}$ and WT mice. B: Overview of representative colon tumors in $\mathrm{CD} 146^{\mathrm{EC}-\mathrm{KO}}$ and WT CAC model mice. Total tumor incidence $(\mathbf{C})$ and incidence of tumors over $4 \mathrm{~mm}^{2}$ (D) in CD146 ${ }^{\mathrm{EC}-\mathrm{KO}}$ and WT CAC model mice. Tumor number of the entire colon was counted, and each tumor size was measured. E: Representative images of immunofluorescence detection of blood vessel density in colon tumors of CD146 $6^{\mathrm{EC}-\mathrm{KO}}$ and WT CAC model mice. CD31 (red) was used as an endothelial cell marker. DAPI (blue) was used for staining cell nuclei. The bar graph shows the quantification of blood vessel density calculated as vessels per $\mathrm{mm}^{2}$. F: Representative images of immunofluorescence detection of $\mathrm{CD}^{+}$(red) leukocyte infiltration into colon tumors of CD146 ${ }^{\mathrm{EC}-\mathrm{KO}}$ and WT CAC model mice. DAPI (blue) was used for staining cell nuclei. The bar graph shows the quantification. G: Bar graphs show the relative mRNA levels of TNF- $\alpha$, IFN- $\gamma$, IL6, IL1- $\beta$, and $\mathrm{COX}-2$ in the colon tissues of $\mathrm{CD} 146^{\mathrm{EC}-\mathrm{KO}}$ and WT CAC model mice as analyzed by real-time RTPCR and normalized to GAPDH. For each cytokine, the mRNA level of nontreated WT mice (naive) was set as $100 \%$. ${ }^{*} P<0.05,{ }^{*} P<<0.01$, $* * * P<0.001(\mathbf{C}-\mathbf{G}) . n=5$ per group $(\mathbf{C}$ and $\mathbf{D})$; $n=3(\mathbf{E}-\mathbf{G})$. Scale bars: $50 \mu \mathrm{m}$ (E and $\mathbf{F})$. observed decreased TNF- $\alpha$, IFN- $\gamma$, and IL6 levels in CD146 ${ }^{\mathrm{EC}-\mathrm{KO}}$ mice (data not shown). As a control, no significant differences in colon histology, colon cytokine mRNA levels, and lymphocyte subpopulations were observed between naive CD146 ${ }^{\mathrm{EC}-\mathrm{KO}}$ mice and WT mice used in the CAC model (Supplemental Figure S5). We next analyzed whether CD146 contributes to the transformation of epithelial cells in a cell autonomous manner. Immunohistochemistry analysis showed no CD146 expression in epithelial cells, which was consistent with the expression pattern of CD146 in human colorectal cancer (Supplemental Figure S6A). Moreover, $\beta$-catenin translocation was analyzed because its overexpression and translocation are important events in colorectal carcinogenesis. In the tumor region of both WT and CD146 ${ }^{\mathrm{EC}-\mathrm{KO}}$ mice, overexpression and translocation of $\beta$-catenin from membrane to cytoplasm and nucleus were observed. However, no significant difference in $\beta$-catenin expression pattern was found between WT and CD146 ${ }^{\text {EC-KO }}$ mice (Supplemental Figure S6B). Meanwhile, immunofluorescence analysis of $\mathrm{Ki}-67$ and TUNEL assay revealed no significant differences in proliferation and apoptosis (Supplemental Figure S6, C and D). These data together suggest that endothelial CD146 facilitates carcinogenesis mainly by promoting inflammation.

\section{CD146 Is Up-Regulated by TNF- $\alpha$ and IL1- $\beta$ through NF- $\kappa B$ Transactivation}

To elucidate the underlying mechanism of endothelial CD146 involvement in colitis and CAC, we examined the expression of CD146 after treating HUVECs and sEnd.1 with different cytokines. We found that TNF- $\alpha$ and IL1- $\beta$, but not IFN- $\gamma$, IL6, or VEGF, could up-regulate CD146 
A

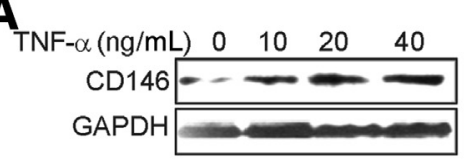

D

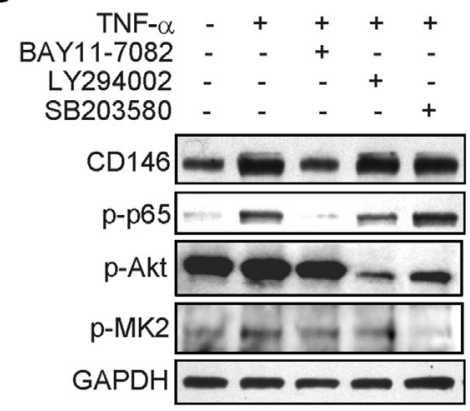

B

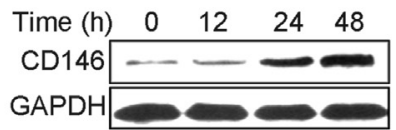

C

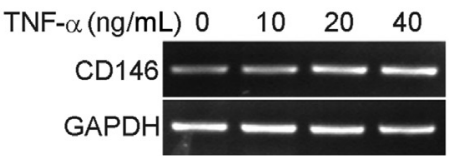

$\mathbf{E}$

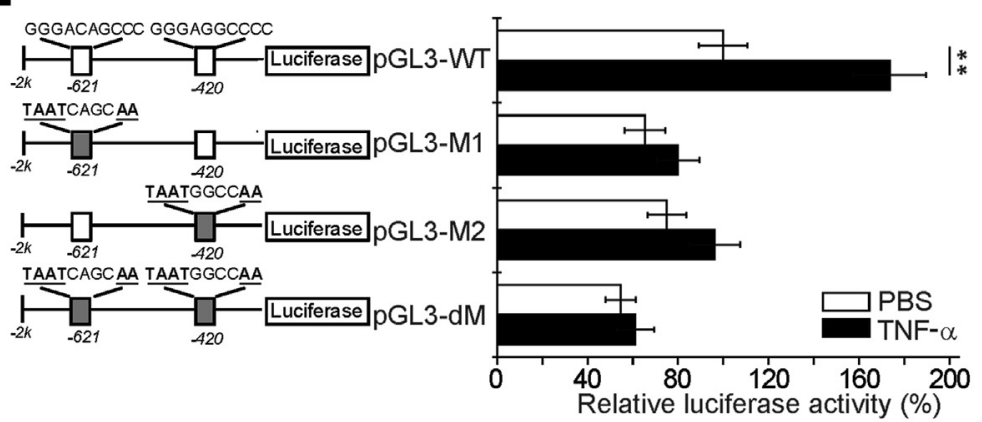

$\mathbf{F}$

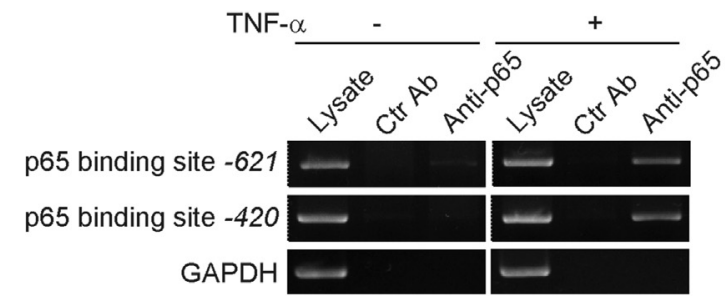

Figure 3 TNF- $\alpha$ up-regulates CD146 expression in human umbilical vein endothelial cells (HUVECs) through NF- $\kappa$ B transactivation. CD146 expression in HUVECs was assayed by Western blot after stimulation with TNF- $\alpha$ at different concentrations for 24 hours (A) and after stimulation of HUVECs with $20 \mathrm{ng} / \mathrm{mL}$ TNF- $\alpha$ for a different time (B). C: CD146 mRNA level was assayed by RT-PCR after stimulation of HUVECs with TNF- $\alpha$ at different concentrations for 12 hours. D: The expression of CD146 and phosphorylation of p65, Akt, and MAPKAPK-2 (MK2, an effecter molecule downstream of p38-MAPK pathway) were assayed by Western blot after stimulation with TNF- $\alpha$ and blocking by pathway inhibitors. BAY11-7082 was used as the NF-KB pathway inhibitor; LY294002, the MAPK-Akt pathway inhibitor; SB203580, the p38-MAPK pathway inhibitor. A-D: GAPDH was used as the internal control. E: Dual luciferase assay of putative NF- $\kappa B$ binding sites in the CD146 promoter. Schematic overview of mutant constructs is shown. The luciferase activity of these constructs was measured and normalized to that of the unstimulated WT construct (pGL3-WT). F: ChIP assay of p65 binding to CD146 promoter using an anti-p65 antibody or an isotypic control (Ctr Ab), followed by PCR amplification of the genomic DNA fragments covering the binding site -621 and -420 . GAPDH was used as the internal control. ${ }^{* *} P<0.01 . n=3(\mathbf{E})$.

expression in HUVEC cells (data not shown). TNF- $\alpha$ upregulated CD146 in a dose- and time-dependent manner, at both the protein and mRNA levels (Figure 3, A-C). Similarly, this phenomenon was observed in HUVECs with IL1- $\beta$ treatment (Supplemental Figure S7, A and B) and mouse endothelioma End.1 cells with mTNF- $\alpha$ treatment (Supplemental Figure S7C).

Because both TNF- $\alpha$ and IL1- $\beta$ activate the NF- $\kappa$ B pathway, we suspected that CD146 up-regulation might be mediated by NF- $\kappa \mathrm{B}$. Indeed, we found that the NF- $\kappa \mathrm{B}$ pathway inhibitor BAY11-7082 blocked CD146 upregulation, whereas the inhibitors of other pathways did not (Figure 3D). In addition, knockdown of NF- $\mathrm{BB}$ subunit p65 also abolished the up-regulation of CD146 by TNF- $\alpha$ (Supplemental Figure S8A). These results indicate that TNF- $\alpha$ induces CD146 up-regulation mainly through NF$\kappa \mathrm{B}$ pathway.

To determine the mechanism of $\mathrm{NF}-\kappa \mathrm{B}$-mediated CD146 up-regulation, we analyzed the promoter region of CD146 (MCAM) using the online database ECR Browser and found two putative NF- $\kappa \mathrm{B}$ binding sites (NF- $\mathrm{KB}$ site 1 at -621 and NF- $\kappa B$ site 2 at -420 ). Using a luciferase reporter gene driven by the CD146 promoter region containing the putative NF- $\kappa \mathrm{B}$ binding sites, we found that TNF- $\alpha$ robustly enhanced the luciferase activity, whereas mutations of the two putative sites abolished such activity (Figure 3E). This result indicates that both the putative NF$\kappa \mathrm{B}$ binding sites are vital for TNF- $\alpha$-induced CD146 expression. To further examine whether NF- $\kappa \mathrm{B}$ directly bound to these putative sites, a ChIP assay was performed against the $\mathrm{p} 65$ subunit of NF- $\kappa \mathrm{B}$. A p65-specific polyclonal antibody enriched the $C D 146$ promoter region in a TNF- $\alpha-$ dependent fashion (Figure 3F). These results indicate that the NF- $\kappa \mathrm{B}$ p65 subunit binds to the sites directly. Taken together, these results suggest that after stimulation, NF- $\kappa \mathrm{B}$ p65 directly binds to the CD146 promoter region and modulates CD146 expression.

\section{Enhanced Endothelial CD146 Expression Promotes Angiogenesis and Endothelium-Leukocyte Interaction}

To determine the effect of the up-regulation of CD146 expression on modulating endothelial functions, we modulated the expression of CD146 on HUVECs with TNF- $\alpha$ 


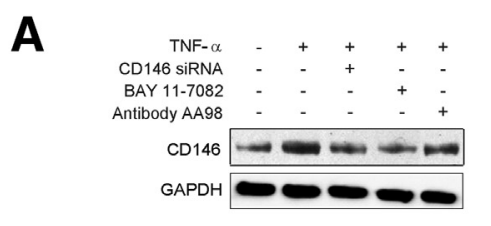

B

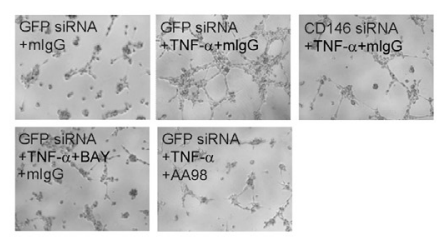

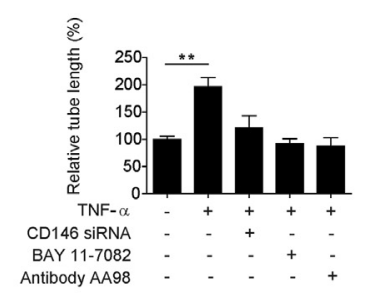

E

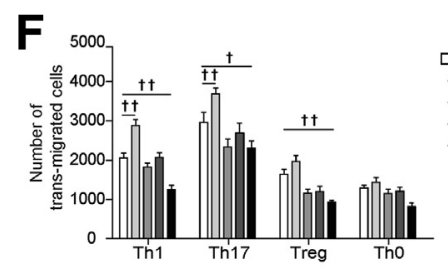

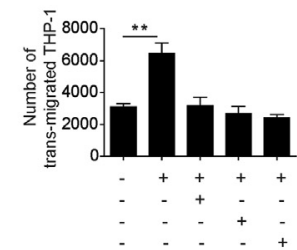

C

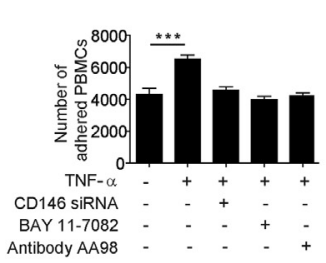

D

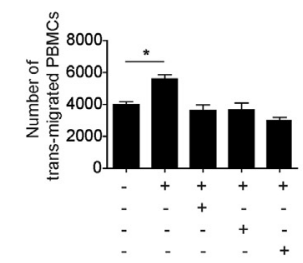

$\square \square \square \square$

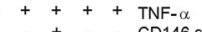

- CD146 siRNA

- BAY 11-7082

Figure 4 Enhanced endothelial CD146 expression promotes endothelial cell tube formation and endothelium-leukocyte interaction. A: CD146 expression was analyzed by Western blot in HUVECs with indicated treatments, before the tube formation and endothelium-leukocyte interaction assays. GFP siRNA and $\mathrm{mIgG}$ were used as control siRNA and antibody, respectively. B: Representative images of tube-formation assay of HUVEC with indicated treatments. The bar graph shows the quantification as relative tube length with the GFP siRNA+mIgG group set as $100 \%$. C: Adhesion assay of fresh isolated PBMCs from a healthy donor adhered to HUVECs with indicated treatments. Transendothelium migration assay of fresh isolated PBMCs (D) and monocyte cell-line THP-1 (E) migrated across an endothelial monolayer formed by HUVECs with the indicated treatments. F: Analysis of in vitro differentiated murine Th1, Th17, Treg, and Th0 lymphocyte transmigration across the endothelial monolayer formed by mouse endothelioma cells (sEnd.1) with the indicated treatments. ${ }^{*} P<0.05,{ }^{*}{ }^{*} P<0.01,{ }^{*}{ }^{*} P<0.001$ (B-E). ${ }^{\dagger} P<0.05,{ }^{\dagger \dagger} P<0.01$ versus the GFP siRNA + mIgG group (F). $n=3(\mathbf{B}-\mathbf{F})$. Original magnification, $\times 100(\mathbf{B})$.

stimulation, and then examined the effect of such treatment first on tube formation. The relative ratio of TNF- $\alpha$ and CD146 siRNA concentration was adjusted to restore CD146 to the baseline level of untreated HUVECs as determined by Western blot (Figure 4A). TNF- $\alpha$ stimulation strongly promoted tube formation of HUVECs on Matrigel (Figure 4B), which appeared to be mediated by CD146 because CD146specific siRNA, NF- $\kappa$ B inhibitor BAY11-7082, or treatment with the anti-CD146 functional antibody AA98 all abolished this effect (Figure 4B and Supplemental Figure S9A). A similar CD146 dependence was observed in TNF- $\alpha$-induced HUVEC migration (data not shown). These data were further confirmed by using a second CD146 siRNA or p65 siRNA (Supplemental Figure S8, B-E). Taken together, these results indicate that enhanced CD146 expression induced by TNF- $\alpha$ promotes angiogenesis.

Furthermore, we analyzed the effect of CD146 on the interaction between endothelium and inflammatory cells. Enhanced endothelial CD146 expression promoted PBMC adhesion to and transmigration across endothelial monolayer (Figure 4, C and D, and Supplemental Figures S6F and S9B). A similar effect was observed when using monocyte THP-1 cells (Figure 4E). Because increased Th1 and Th17 lymphocyte infiltration was observed in the lamina propria from WT mice compared to CD146 ${ }^{\mathrm{EC}-\mathrm{KO}}$ mice, we suspected that CD146 on endothelial cells might facilitate recruitment of these proinflammatory lymphocytes. To test this possibility, a transendothelium migration assay was performed with in vitro differentiated Th1, Th17, Treg, and Th0 cells. Interestingly, endothelial cells with TNF- $\alpha-$ induced CD146 expression recruited more Th1 and Th17 lymphocytes than Treg and Th0 cells, which could be blocked by CD146 knockdown, NF- $\mathrm{B}$ inhibition, or antibody AA98 (Figure 4F), suggesting that enhanced expression of endothelial CD146 facilities proinflammatory Th1 and Th17 infiltration.

CD146 has been reported to be expressed in some subsets of leukocytes. We first tested whether AA98 affects the function of $\mathrm{CD}_{146^{-}}$and $\mathrm{CD} 146^{+}$lymphocytes. Murine $\mathrm{CD}_{146}{ }^{-}$and $\mathrm{CD}_{146^{+}}$lymphocytes isolated by flow cytometry were treated with AA98 or mIgG for 48 hours before they were used to transmigrate across the sEnd.1 endothelial monolayer. CD $146^{+}$lymphocytes were observed to have a greater transmigrating ability than $\mathrm{CD}_{146^{-}}$lymphocytes. However, AA98 did not affect the transmigration of CD146 ${ }^{+}$lymphocyte (Supplemental Figure S10). Also, AA98 had no effect on differentiation and proliferation of lymphocyte in vitro as we previously reported. ${ }^{31}$ We next examined whether AA98 affects the function of macrophage. We found that AA98 did not affect LPS-induced NF- $\kappa$ B activation and cytokine production in peritoneal exudate cells (Supplemental Figure S11, A-C). In addition, treating peritoneal exudate cells with AA98 did not affect its migration (Supplemental Figure S11D). Similar results were found when we treated bone marrow-derived macrophages with AA98 (data not shown). Therefore, although CD146 is expressed on subsets of lymphocytes and macrophages, our data show that AA98 does not affect their function. All together, these data indicate that enhanced endothelial CD146 expression facilitates angiogenesis, as well as 
endothelium-leukocyte interactions, whereas anti-CD146 antibody AA98 predominantly targets endothelial CD146, rather than CD146 on leukocytes, to function.

\section{Targeting CD146 by Antibody AA98 Attenuates Colitis and Prevents CAC in Murine Models}

Because CD146 plays an important role in colitis pathogenesis and AA98 blocks CD146 function in in vitro experiments, we examined the therapeutic value of antiCD146 antibody AA98 in mouse models. By administered AA98 or an isotypic control ( $\mathrm{mIgG}$ ) preventively to the DSStreated mice (during the DSS induction process), we found that AA98 significantly alleviated disease severity (Figure 5A). To mimic the long-lasting and relapsing property of IBD, we established a chronic colitis murine model, and administrated AA98 after the onset of disease. Because IBD is a clinically heterogeneous disease with complex mechanisms, a combination of drugs targeting distinct biomarkers might be considered a potential approach. Thus, we also tested the combination treatment of anti-CD146 antibody AA98 and anti-TNF- $\alpha$ antibody V1q in this chronic colitis murine model. DAI and histological score were dramatically reduced in the AA98 treatment group and the V1q treatment group, especially the combination treatment (AA98+V1q) group, compared to the $\mathrm{mIgG}$ treatment group (Figure 5B). Consistent with the observation in CD146 ${ }^{\mathrm{EC}-\mathrm{KO}}$ colitis model mice, we found a decrease in blood vessels and lymphocytic cell infiltration, both in AA98-treated and
V1q-treated mice, whereas a more significant decrease was observed in the combination treatment group (Supplemental Figure S12, A and B). In addition, the expression levels of proinflammatory cytokines were also reduced (Supplemental Figure S12C). These data indicate that AA98, especially in combination with anti-TNF- $\alpha$ antibody, could be an efficient treatment for colitis.

Furthermore, because AA98 treatment appeared to ameliorate the inflammatory response in colitis, we tested whether it could protect mice with colitis from developing tumors by treating CAC mice with either $\mathrm{mIgG}$ or AA98 during the DSS induction process. Interestingly, tumor incidence and tumor volume were drastically reduced in AA98-treated mice (Figure 5C). Collectively, these data indicate the therapeutic value of anti-CD146 antibody AA98 in treating colitis and preventing CAC.

\section{Discussion}

CD146 has been reported to be associated with inflammation diseases through unknown mechanisms. ${ }^{23,26,27}$ In this study, we show that enhanced CD146 expression on endothelial cells facilitates angiogenesis and leukocyte extravasation, suggesting that endothelial CD146 may serve as a critical molecular promoting inflammation and linking chronic colitis and CAC. Notably, targeting CD146 by either antibody blocking or the use of a conditional knockout significantly alleviated inflammation during acute and chronic colitis, and also decreased tumor incidence and tumor volume in a murine
A
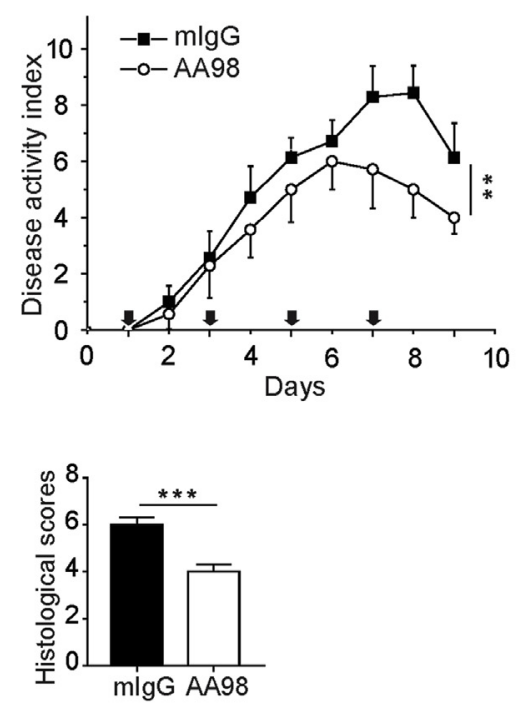

B
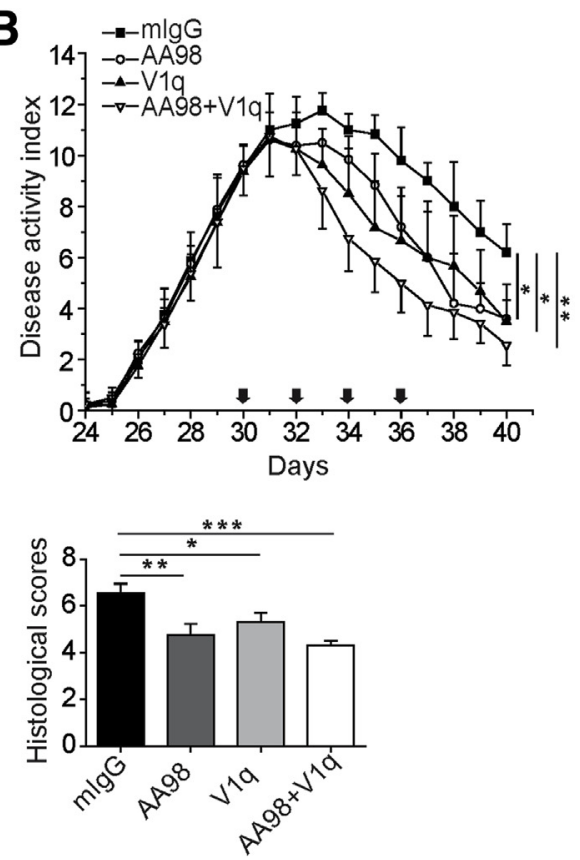

C

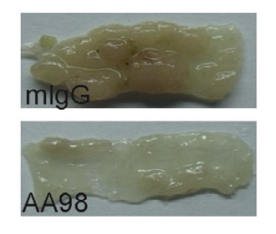

Tumor number

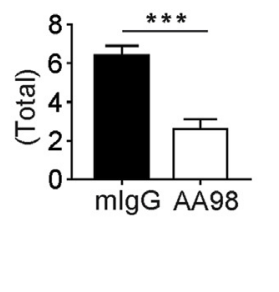

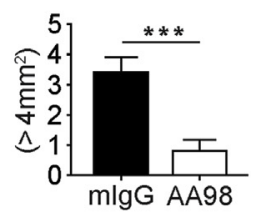

Figure 5 Treatment with AA98 attenuates colitis and prevents colitis-associated carcinogenesis. A: Comparison of disease activity index and histological scores between colitis model mice with AA98 or mIgG preventive treatment. The time of antibody injections (arrows). B: Comparison of disease activity index of the last cycle (day 24 to 41) of DSS induction and the corresponding histological score (based on antibody treatment) among chronic colitis model mice with indicated antibody treatments. The time of antibody injections (arrows). C: Total tumor incidence and incidence of tumors over $4 \mathrm{~mm}^{2}$ in AOM-DSS-induced CAC model mice with mIgG or AA98 treatment. ${ }^{* *} P<0.01,{ }^{* * *} P<0.001$ versus the mIgG treatment group. $n=6$ per group $(\mathbf{A}$ and $\mathbf{B}) ; n=5$ (C). 
CAC model. This is the first evidence that the modulation of inflammation and angiogenesis simultaneously by targeting a single adhesion molecule on endothelial cells can prevent CAC.

Our previous study established CD146 as a signaling receptor, more interestingly, a VEGF coreceptor ${ }^{19}$ on the surface of endothelial cells, capable of activating the p38/IKK/ $\mathrm{NF}-\kappa \mathrm{B}$ signaling cascade, inducing endothelial activation and cytoskeleton remodeling, leading to tumor angiogenesis. ${ }^{15-17}$ However, the regulatory mechanisms of CD146 and its function in inflammation remain unknown. Here, we study the upstream regulation mechanism of CD146 and present evidence that endothelial CD146 expression is induced directly by NF- $\kappa \mathrm{B}$ transactivation stimulated by TNF- $\alpha$. In turn, CD146 overexpression on endothelial cells promotes angiogenesis, as well as facilitates recruitment of proinflammatory Th1 and Th17 lymphocytes to the sites of inflammation. Such a dual function of endothelial CD146 could exacerbate the inflammation in the affected tissues, resulting in a pathological cycle leading the initial inflammation to chronic inflammation and at last to carcinogenesis. These results explained the function and regulation mechanism of enhanced CD146 expression on endothelial cells during IBD, which were previously observed by Tsiolakidou et $\mathrm{al}^{23}$ and Bardin et $\mathrm{al}^{24}$ in intestinal biopsies from IBD patients. In addition, it further provides the evidence that modulation of the inflammatory environment by targeting vascular endothelial cells could reduce the incidence of inflammation-associated carcinogenesis.

Here, we focused on the function of CD146 in endothelial cells. However, CD146 expression has also been reported on Th17 lymphocytes ${ }^{41}$ and certain macrophage subpopulations. ${ }^{42,43}$ As shown in our recent publication, ${ }^{31}$ the knockout of endothelial CD146 in CD146 ${ }^{\mathrm{EC}-\mathrm{KO}}$ mice does not impair $\mathrm{CD}_{146^{+}}$lymphocytes. Furthermore, the antiCD146 antibody AA98 does not affect the proliferation or activation of either $\mathrm{CD} 146^{-}$or $\mathrm{CD} 146^{+}$lymphocytes. Interestingly, we found that pretreating $\mathrm{CD} 146^{+}$lymphocytes alone with AA98 did not affect their ability of transendothelium migration, whereas pretreating endothelial cells alone did block leukocyte transmigration. In addition, we found that AA98 did not affect LPS-induced NF- $\kappa$ B activation and cytokine production in peritoneal exudate or bone marrow-derived macrophages. Also, treating macrophages with AA98 did not block their migration. Although the role of CD146 in leukocytes remains to be determined, our data suggest that enhanced endothelial CD146 expression facilitates leukocyte (either $\mathrm{CD}_{146^{-}}$or $\mathrm{CD} 146^{+}$) transendothelial migration. In addition, the AA98 antibody selectively targets endothelial CD146, but not CD146 on lymphocytes or macrophages, to inhibit the extravasation of leukocytes.

Of note, our $\mathrm{CD} 146^{\mathrm{EC}-\mathrm{KO}}$ mice were generated using a $\mathrm{Tg}(\mathrm{Tek}-\mathrm{Cr}$ ) system. Because Tie2 (Tek) was reportedly expressed on a subset macrophage, we cannot exclude a possible effect of $\mathrm{CD}_{146^{+}}$macrophages involved in colitis and CAC. However, our data have shown that blocking CD146 by AA98 did not have an effect on activation and migration of macrophages, whereas AA98 did alleviate colitis and CAC. Therefore, we suspect that the CD146 expressed on certain macrophages and lymphocytes may play a minor role compared with endothelial CD146. Detailed analysis of CD146 on macrophages awaits the generation of macrophage-specific CD146 knockout mice.

The current treatment of IBD mainly focuses on inhibition of cytokines. Infliximab, an antibody against TNF- $\alpha$, was approved by the US Food and Drug Administration for treating UC. Many inhibitors and antibodies against TNF- $\alpha$ (Etanercept, Onercept), IFN- $\gamma$ (Fontolizumab), IL12p40, and IL6 receptor are now under clinical evaluation. ${ }^{44}$ However, side effects such as increased risk of infection and even lymphoma have been indicated. ${ }^{44}$ Moreover, clinical trial data suggest that a considerable proportion of patients receiving anti-TNF- $\alpha$ therapy may become refractive in the first few years. ${ }^{45}$ Therefore, anti-adhesion molecule therapy could be an alternative therapeutic intervention. In this study, we tested the efficacy of our anti-CD146 antibody AA98 and also a combination treatment of anti-TNF- $\alpha$ and antiCD146. AA98 markedly attenuated experimental colitis, and the combination of anti-CD146 and anti-TNF- $\alpha$ had an even more significant effect. Histological examination revealed that AA98 treatment preserved a more integral epithelial structure with less leukocyte infiltration, although the change in DAI indicated that targeting TNF- $\alpha$ ameliorated the clinical symptoms more rapidly than AA98 treatment. This may be due to the different mechanisms underlying the action of these two molecules. Thus, the combination therapy of anti-CD146 and anti-TNF- $\alpha$ may have a synergistic effect and hold a promising potential.

In this study, we propose that CD146 plays its role in promoting CAC mainly by facilitating the inflammatory environment, because no CD146 expression was found in epithelial cells of the tumor. It has been now well accepted that decreased inflammation leads to decreased epithelial proliferation and decreased DNA damage, which results in reduced carcinogenesis. Thus, any agent that reduces inflammation in the AOM-DSS model would be expected to reduce CAC, making it impossible to distinguish between the effects of targeting CD146 on colitis activity and a separate antineoplastic effect. However, a unique characteristic of CD146 is that CD146 plays a dual role in endothelial cells-facilitating leukocyte extravasations and angiogenesis simultaneously. Because the development of tumor depends indispensably on angiogenesis, ${ }^{46}$ targeting endothelial CD146 not only affects the inflammatory environment, but also prohibits tumor development directly. Nevertheless, further study should be done to fully understand the function and mechanism of CD146 in the course of tumor development.

Taken together, our data demonstrate that endothelial CD146 plays a vital role in inflammation. Its involvement in the recruitment of inflammatory lymphocytes and promotion 
of angiogenesis, may serve as a critical linking between colitis and colorectal carcinogenesis. Targeting CD146 may be a therapeutic option in treating colitis, as well as a preventative method for colitis-associated colorectal carcinogenesis.

\section{Supplemental Data}

Supplemental material for this article can be found at http://dx.doi.org/10.1016/j.ajpath.2014.01.031.

\section{References}

1. Grivennikov SI, Greten FR, Karin M: Immunity, inflammation, and cancer. Cell 2010, 140:883-899

2. Danese S, Mantovani A: Inflammatory bowel disease and intestinal cancer: a paradigm of the Yin-Yang interplay between inflammation and cancer. Oncogene 2010, 29:3313-3323

3. Kaser A, Zeissig S, Blumberg RS: Inflammatory bowel disease. Annu Rev Immunol 2011, 28:573-621

4. Askling J, Dickman PW, Karlen P, Brostrom O, Lapidus A, Lofberg R, Ekbom A: Colorectal cancer rates among first-degree relatives of patients with inflammatory bowel disease: a population-based cohort study. Lancet 2001, 357:262-266

5. Terzic J, Grivennikov S, Karin E, Karin M: Inflammation and colon cancer. Gastroenterology 2010, 138:2101-2114.e5

6. Greten FR, Eckmann L, Greten TF, Park JM, Li ZW, Egan LJ, Kagnoff MF, Karin M: IKKbeta links inflammation and tumorigenesis in a mouse model of colitis-associated cancer. Cell 2004, 118: 285-296

7. Popivanova BK, Kitamura K, Wu Y, Kondo T, Kagaya T, Kaneko S, Oshima M, Fujii C, Mukaida N: Blocking TNF-alpha in mice reduces colorectal carcinogenesis associated with chronic colitis. J Clin Invest 2008, 118:560-570

8. Waldner MJ, Wirtz S, Jefremow A, Warntjen M, Neufert C, Atreya R, Becker C, Weigmann B, Vieth M, Rose-John S, Neurath MF: VEGF receptor signaling links inflammation and tumorigenesis in colitisassociated cancer. J Exp Med 2010, 207:2855-2868

9. Danese S, Sans M, Spencer DM, Beck I, Donate F, Plunkett ML, de la Motte C, Redline R, Shaw DE, Levine AD, Mazar AP, Fiocchi C: Angiogenesis blockade as a new therapeutic approach to experimental colitis. Gut 2007, 56:855-862

10. Huang Z, Zuo L, Zhang Z, Liu J, Chen J, Dong L, Zhang J: 3,3'Diindolylmethane decreases VCAM-1 expression and alleviates experimental colitis via a BRCA1-dependent antioxidant pathway. Free Radic Biol Med 2011, 50:228-236

11. Taniguchi T, Tsukada H, Nakamura H, Kodama M, Fukuda K, Saito T, Miyasaka M, Seino Y: Effects of the anti-ICAM-1 monoclonal antibody on dextran sodium sulphate-induced colitis in rats. J Gastroenterol Hepatol 1998, 13:945-949

12. Rijcken E, Mennigen RB, Schaefer SD, Laukoetter MG, Anthoni C, Spiegel HU, Bruewer M, Senninger N, Krieglstein CF: PECAM-1 (CD 31) mediates transendothelial leukocyte migration in experimental colitis. Am J Physiol Gastrointest Liver Physiol 2007, 293: G446-G452

13. Farkas S, Hornung M, Sattler C, Edtinger K, Steinbauer M, Anthuber M, Schlitt HJ, Herfarth H, Geissler EK: Blocking MAdCAM-1 in vivo reduces leukocyte extravasation and reverses chronic inflammation in experimental colitis. Int J Colorectal Dis 2006, 21:71-78

14. Ouhtit A, Gaur RL, Abd Elmageed ZY, Fernando A, Thouta R, Trappey AK, Abdraboh ME, El-Sayyad HI, Rao P, Raj MG: Towards understanding the mode of action of the multifaceted cell adhesion receptor CD146. Biochim Biophys Acta 2009, 1795:130-136
15. Bu P, Gao L, Zhuang J, Feng J, Yang D, Yan X: Anti-CD146 monoclonal antibody AA98 inhibits angiogenesis via suppression of nuclear factor-kappaB activation. Mol Cancer Ther 2006, 5:2872-2878

16. Bu P, Zhuang J, Feng J, Yang D, Shen X, Yan X: Visualization of CD146 dimerization and its regulation in living cells. Biochim Biophys Acta 2007, 1773:513-520

17. Zheng C, Qiu Y, Zeng Q, Zhang Y, Lu D, Yang D, Feng J, Yan X: Endothelial CD146 is required for in vitro tumor-induced angiogenesis: the role of a disulfide bond in signaling and dimerization. Int $\mathrm{J}$ Biochem Cell Biol 2009, 41:2163-2172

18. Zhuang J, Jiang T, Lu D, Luo Y, Zheng C, Feng J, Yang D, Chen C, Yan X: NADPH oxidase 4 mediates reactive oxygen species induction of CD146 dimerization in VEGF signal transduction. Free Radic Biol Med 2011, 49:227-236

19. Jiang T, Zhuang J, Duan H, Luo Y, Zeng Q, Fan K, Yan H, Lu D, Ye Z, Hao J, Feng J, Yang D, Yan X: CD146 is a coreceptor for VEGFR-2 in tumor angiogenesis. Blood 2012, 120:2330-2339

20. Luo Y, Zheng C, Zhang J, Lu D, Zhuang J, Xing S, Feng J, Yang D, Yan X: Recognition of CD146 as an ERM-binding protein offers novel mechanisms for melanoma cell migration. Oncogene 2012, 31: 306-321

21. Zeng Q, Li W, Lu D, Wu Z, Duan H, Luo Y, Feng J, Yang D, Fu L, Yan X: CD146, an epithelial-mesenchymal transition inducer, is associated with triple-negative breast cancer. Proc Natl Acad Sci U S A 2012, 109:1127-1132

22. Yan X, Lin Y, Yang D, Shen Y, Yuan M, Zhang Z, Li P, Xia H, Li L, Luo D, Liu Q, Mann K, Bader BL: A novel anti-CD146 monoclonal antibody, AA98, inhibits angiogenesis and tumor growth. Blood 2003, 102:184-191

23. Tsiolakidou G, Koutroubakis IE, Tzardi M, Kouroumalis EA: Increased expression of VEGF and CD146 in patients with inflammatory bowel disease. Dig Liver Dis 2008, 40:673-679

24. Bardin N, Reumaux D, Geboes K, Colombel JF, Blot-Chabaud M, Sampol J, Duthilleul P, Dignat-George F: Increased expression of CD146, a new marker of the endothelial junction in active inflammatory bowel disease. Inflamm Bowel Dis 2006, 12:16-21

25. Neidhart M, Wehrli R, Bruhlmann P, Michel BA, Gay RE, Gay S: Synovial fluid CD146 (MUC18), a marker for synovial membrane angiogenesis in rheumatoid arthritis. Arthritis Rheum 1999, 42: 622-630

26. Daniel L, Bardin N, Moal V, Dignat-George F, Berland Y, FigarellaBranger D: Tubular CD146 expression in nephropathies is related to chronic renal failure. Nephron 2005, 99:e105-e111

27. Feng L, Matsumoto C, Schwartz A, Schmidt AM, Stern DM, PileSpellman J: Chronic vascular inflammation in patients with type 2 diabetes: endothelial biopsy and RT-PCR analysis. Diabetes Care 2005, 28:379-384

28. Zhang Y, Zheng C, Zhang J, Yang D, Feng J, Lu D, Yan X: Generation and characterization of a panel of monoclonal antibodies against distinct epitopes of human CD146. Hybridoma 2008, 27:345-352

29. Jansen MJ, Hendriks T, Hermsen R, Van der Meer JW, Goris RJ: A monoclonal antibody against tumour necrosis factor-alpha improves survival in experimental multiple organ dysfunction syndrome. Cytokine 1998, 10:904-910

30. Kang Y, Wang F, Feng J, Yang D, Yang X, Yan X: Knockdown of CD146 reduces the migration and proliferation of human endothelial cells. Cell Res 2006, 16:313-318

31. Duan H, Xing S, Luo Y, Feng L, Gramaglia I, Zhang Y, Lu D, Zeng Q, Fan K, Feng J, Yang D, Qin Z, Couraud PO, Romero IA, Weksler B, Yan X: Targeting endothelial CD146 attenuates neuroinflammation by limiting lymphocyte extravasation to the CNS. Sci Rep 2013, 3:1687

32. Wirtz S, Neufert C, Weigmann B, Neurath MF: Chemically induced mouse models of intestinal inflammation. Nat Protoc 2007, 2:541-546

33. Obermeier F, Kojouharoff G, Hans W, Scholmerich J, Gross V, Falk W: Interferon-gamma (IFN-gamma)- and tumour necrosis factor (TNF)-induced nitric oxide as toxic effector molecule in chronic 
dextran sulphate sodium (DSS)-induced colitis in mice. Clin Exp Immunol 1999, 116:238-245

34. Moolenbeek C, Ruitenberg EJ: The "Swiss roll": a simple technique for histological studies of the rodent intestine. Lab Anim 1981, 15: $57-59$

35. Vermeulen PB, Gasparini G, Fox SB, Colpaert C, Marson LP, Gion M, Belien JA, de Waal RM, Van Marck E, Magnani E, Weidner N, Harris AL, Dirix LY: Second international consensus on the methodology and criteria of evaluation of angiogenesis quantification in solid human tumours. Eur J Cancer 2002, 38:1564-1579

36. Weigmann B, Tubbe I, Seidel D, Nicolaev A, Becker C, Neurath MF: Isolation and subsequent analysis of murine lamina propria mononuclear cells from colonic tissue. Nat Protoc 2007, 2: $2307-2311$

37. Monteleone I, Pallone F, Monteleone G: Th17-related cytokines: new players in the control of chronic intestinal inflammation. BMC Med 2011, 9:122

38. Neurath MF, Fuss I, Kelsall BL, Stuber E, Strober W: Antibodies to interleukin 12 abrogate established experimental colitis in mice. J Exp Med 1995, 182:1281-1290

39. Neurath MF, Pettersson S, Meyer zum Buschenfelde KH, Strober W: Local administration of antisense phosphorothioate oligonucleotides to the p65 subunit of NF-kappa B abrogates established experimental colitis in mice. Nat Med 1996, 2:998-1004
40. Fukata M, Hernandez Y, Conduah D, Cohen J, Chen A, Breglio K, Goo T, Hsu D, Xu R, Abreu MT: Innate immune signaling by Toll-like receptor-4 (TLR4) shapes the inflammatory microenvironment in colitis-associated tumors. Inflamm Bowel Dis 2009, 15:997-1006

41. Dagur PK, Biancotto A, Wei L, Sen HN, Yao M, Strober W, Nussenblatt RB, Philip McCoy J Jr: MCAM-expressing CD4(+) T cells in peripheral blood secrete IL-17A and are significantly elevated in inflammatory autoimmune diseases. J Autoimmun 2011, 37:319-327

42. Kratzer A, Chu HW, Salys J, Moumen Z, Leberl M, Bowler R, Cool C, Zamora M, Taraseviciene-Stewart L: Endothelial cell adhesion molecule CD146: implications for its role in the pathogenesis of COPD. J Pathol 2013, 230:388-398

43. Wu Q, Case SR, Minor MN, Jiang D, Martin RJ, Bowler RP, Wang J, Hartney J, Karimpour-Fard A, Chu HW: A novel function of MUC18: amplification of lung inflammation during bacterial infection. Am J Pathol 2013, 182:819-827

44. Nakamura K, Honda K, Mizutani T, Akiho H, Harada N: Novel strategies for the treatment of inflammatory bowel disease: selective inhibition of cytokines and adhesion molecules. World J Gastroenterol 2006, 12:4628-4635

45. Ghosh S, Panaccione R: Anti-adhesion molecule therapy for inflammatory bowel disease. Therap Adv Gastroenterol 2010, 3:239-258

46. Folkman J: Tumor angiogenesis: therapeutic implications. N Engl J Med 1971, 285:1182-1186 